\title{
Molecular apocrine differentiation is a common feature of breast cancer in patients with germline PTEN mutations
}

\author{
Guillaume Banneau', Mickaël Guedj², Gaëtan MacGrogan ${ }^{1,3}$, Isabelle de Mascarel ${ }^{3}$, Valerie Velasco ${ }^{3}$, \\ Renaud Schiappa ${ }^{2}$, Valerie Bonadona ${ }^{4}$, Albert David ${ }^{5}$, Catherine Dugast ${ }^{6}$, Brigitte Gilbert-Dussardier ${ }^{7}$, \\ Olivier Ingster ${ }^{8}$, Pierre Vabres ${ }^{9}$, Frederic Caux ${ }^{10}$, Aurelien de Reynies ${ }^{2}$, Richard Iggo ${ }^{1}$, Nicolas Sevenet ${ }^{1,11}$, \\ Françoise Bonnet ${ }^{1,11}$, Michel Longy ${ }^{1,11^{*}}$
}

\begin{abstract}
Introduction: Breast carcinoma is the main malignant tumor occurring in patients with Cowden disease, a cancerprone syndrome caused by germline mutation of the tumor suppressor gene PTEN characterized by the occurrence throughout life of hyperplastic, hamartomatous and malignant growths affecting various organs. The absence of known histological features for breast cancer arising in a PTEN-mutant background prompted us to explore them for potential new markers.
\end{abstract}

Methods: We first performed a microarray study of three tumors from patients with Cowden disease in the context of a transcriptomic study of 74 familial breast cancers. A subsequent histological and immunohistochemical study including 12 additional cases of Cowden disease breast carcinomas was performed to confirm the microarray data.

Results: Unsupervised clustering of the 74 familial tumors followed the intrinsic gene classification of breast cancer except for a group of five tumors that included the three Cowden tumors. The gene expression profile of the Cowden tumors shows considerable overlap with that of a breast cancer subgroup known as molecular apocrine breast carcinoma, which is suspected to have increased androgenic signaling and shows frequent ERBB2 amplification in sporadic tumors. The histological and immunohistochemical study showed that several cases had apocrine histological features and expressed GGT1, which is a potential new marker for apocrine breast carcinoma.

Conclusions: These data suggest that activation of the ERBB2-PI3K-AKT pathway by loss of PTEN at early stages of tumorigenesis promotes the formation of breast tumors with apocrine features.

\section{Introduction}

The classification of breast cancer was recently enriched by the addition of gene expression microarray data for the main histopathological tumor types [1]. The most widely used transcriptomic classification, the Intrinsic Gene Set or Stanford classification, divides breast cancer into luminal A, luminal B, basal-like, normal-like and HER2 classes [2-4]. It is based on studies of sporadic tumors, and reflects mainly tumor cell type and HER2

\footnotetext{
* Correspondence: longy@bergonie.org

'INSERM U916, Université de Bordeaux, Institut Bergonié, 229 cours de l'Argonne, 33000, Bordeaux, France

Full list of author information is available at the end of the article
}

status. Few studies have looked at the gene expression profile of breast cancers arising in patients with a familial predisposition to cancer. In those studies, the tumors arising in patients with germline BRCA1 mutations frequently had a basal-like phenotype, whereas BRCA2related tumors had no particular type or a luminal $B$ type [5]. Little is known about the transcriptomic profile of breast cancers caused by germline mutations in genes other than BRCA1 and BRCA2. Cowden disease (MIM $158350)$ is a cancer predisposition syndrome caused by germline mutation of the tumor suppressor gene PTEN [6,7]. In addition to hamartomas and hyperplasias affecting multiple organs, patients develop breast cancer with 
a cumulative risk $>50 \%$ at age 70 [8]. To investigate the pathogenesis of breast cancer in Cowden disease, we have analyzed the gene expression profile of three breast carcinomas from Cowden disease patients with known germline PTEN mutations.

\section{Materials and methods \\ Patients and samples}

To allow us to identify distinctive features of PTENrelated tumors, the analysis was performed in the context of a panel of 74 tumors from patients with a familial clustering of breast cancer, including 7 with $B R C A 1$ and 5 with $B R C A 2$ mutations. All of the samples were taken from the Bergonié Cancer Institute tumor bank. The patients belong to families with either i) at least three cancer affected first degree relatives including at least two with breast cancer; or ii) two first degree relatives with breast cancer at a young age of onset (mean age up to 50 years). Only one tumor sample per patient was tested. In most cases only one tumor was available per family, but in one family, three samples were available, and in seven other families, including one Cowden family, two samples were available. Major demographic, clinical and pathological features are listed in Table S1 in Additional file 1. All patients agreed to the use of their samples for research purposes, in compliance with the French law on tumor banks (law $\mathrm{n}^{\circ}$ 2004-800). The PTEN mutation search was made after signed informed consent in the context of a medical genetic diagnosis of suspected Cowden disease, in compliance with the French law on genetic testing (law $n^{\circ}$ 94-654).

\section{Gene expression analysis}

After assessment of tumor cellularity in each sample on haematoxylin-eosin stained frozen sections, Rneasy Mini Kits (Qiagen S.A., Courtaboeuf, France) were used to extract total RNA from samples ground to powder while frozen. RNA quality was assessed using the Agilent 2100 Bioanalyzer (Agilent Technologies France, Massy, France). Gene-expression analyses were performed by the IGBMC and Génopole Alsace-Lorraine Affymetrix service using Affymetrix U133 Plus 2.0 genechip microarrays(Affymetrix UK Ltd, High Wycombe, UK). The transcriptomics data are available in ArrayExpress database [9] - (accession number: [E-TABM-854]) or in the CIT database [10].

\section{Mutation analysis}

DNA was purified from leucocytes and tumors by phenolchloroform extraction. PTEN point mutations were identified by denaturing gradient gel electrophoresis (DGGE) screening followed by sequencing of the variants on an ABI DNA sequencing machine [11]. Large rearrangements were screened for by quantitative multiplex PCR [12].

\section{Immunohistochemistry}

Immunohistochemical detection was performed with the REAL EnVision Detection System (Dako ${ }^{\oplus}$, Trappes, France). Tissue microarraying was performed with a tissue arrayer (MTA Booster 01, Alphelys, Plaisir, France). For each sample, four $0.6 \mathrm{~mm}$ core sections of tissue were extracted from paraffin-embedded tissues. The following antibodies were used: anti-GGT1 (SigmaAldrich $^{\oplus}$ St. Louis, MO, USA, clone 1F9); anti-PTEN (Cascade Biosciences ${ }^{\mathrm{TM}}$ Winchester, MA, USA, clone 6H2.1); anti-Estrogen receptor (Dako ${ }^{\oplus}$ Trappes, France, clone 1D5); anti-Progesterone receptor (Dako ${ }^{\circ}$, Trappes, France, clone PgR636); anti-HER2 (Dako ${ }^{\circ}$, Trappes, France, cloneAO485); anti-Androgen Receptor (Dako ${ }^{\circ}$ Trappes, France, clone 1D5); anti-GCDFP15 (Signet ${ }^{\mathrm{TM}}$, Dedham, MA, USA, clone D6); anti-EGFR (Ventana ${ }^{\oplus}$, Illkrich, France, clone 3C6). Two parameters were evaluated for each antibody: (i) the percentage of tumoral cells showing a positive signal and (ii) the intensity of that signal classed as low (1), moderate (2) or high (3). ERBB2 expression was evaluated according to the Herceptest scoring system. For ER, PR, AR, PTEN, GCDFP15, GGT1 and EGFR, the following scoring was used: score 0 , no tumor cells with any positivity; score1, 1 to $10 \%$ of tumors cells showing a positive signal; score 2,11 to $100 \%$ of tumor cells showing a positive signal, whatever associated intensity of staining.

\section{Array CGH analyses}

Array CGH was performed on human Integrachip V7 slides (Integragen SA, Evry, France, [13]). IntegraChip V7 is composed of 5878 BAC clones with a median of $0.5 \mathrm{Mb}$ between clones. BAC clones are spotted in quadruplicate. A pool of 19 normal DNAs was used as reference DNA. DNA was labelled by random priming with cyanine 5 for reference DNA (Cy5) and cyanine 3 for tumor DNA (Cy3). Hybridizations were performed according to the manufacturer's recommendations. Slides were scanned with an Axon 4000B scanner (Axon Instruments Inc., Union City, CA, USA) and acquired images were analyzed with GenePix Pro 5.1 image analysis software to perform segmentation and to determine the mean intensities for the Cy3 and Cy5 signals of each BAC clone.

The CAPweb (Copy number Array analysis Platform on the web) platform developed by Institut Curie [14] was used for normalization (MANOR package), gain, loss or normal clone status assignment and breakpoint detection (GLAD package). The following default filtering parameters were retained: signal to noise ratio less than 3, standard deviation of replicates greater than 0.1 and exclusion of clones with missing values in over $50 \%$ of the tumors. Graphical representation of genomic alterations was performed with VAMP software (Institut 
Curie, Paris, France) $[15,16]$. The definition of gains and losses was based on median Cy3 to Cy5 log ratios greater than 1.2 and less than 0.8 respectively. Amplicons were defined by median log ratios greater than 2 . The array CGH data are available in the ArrayExpress database (accession number: E-TABM-854) [9] or in the CIT database [10].

\section{Statistical analyses}

Except where indicated, all transcriptomic analyses were carried out using R packages $[17,18]$ or original R code. Raw gene expression data were normalized using the robust multi-array average (RMA) method from the $\mathrm{R}$ package affy [19]. Probe sets for control genes and those for which the 90th percentile of the $\log _{2}$ intensity was < 10 were removed, yielding a total of 48,927 probe sets.

\section{Unsupervised classification of samples}

Probe sets were selected for clustering based on the following criteria: (i) $P$-value of a variance test less than 0.01 and (ii) a robust coefficient of variation $(\mathrm{rCV})$ less than 10 but greater than the $95^{\text {th }}$ percentile of the rCV. For the variance test, we selected probe sets $(\mathrm{P})$ whose variance across the samples was different from the median of the variances (Varmed) of all the probe sets. The statistic used was $(\mathrm{n}-1)^{\prime} \operatorname{Var}(\mathrm{P}) / \operatorname{Varmed}$, where $\mathrm{n}$ refers to the number of samples. This statistic was compared to a percentile of the Chi-square distribution with (n-1) degrees of freedom and yielded a $P$-value for each probe set. This criterion is the same as that used in the filtering tool of the BRB ArrayTools software [20]. The rCV was calculated as follows: having ordered the intensity values of the $\mathrm{n}$ samples from minimum to maximum, we eliminated the minimum and maximum values and calculated the coefficient of variation for the remaining values. After filtering, we were left with 2,447 probe sets which were used for agglomerative hierarchical clustering using Ward's linkage and 1-Pearson correlation as a distance metric. The resulting dendrogram is used to order the genes and samples in the heatmap in Figure 1.

\section{Assignment of samples to Stanford classes}

In order to assign the tumor samples to the five subtypes in the Stanford classification, we calculated the Pearson correlation between each sample and each of the five centroids $[4,21]$. The probe sets in the two datasets were matched based on the UniGene IDs, resulting in a total of 334 common genes. Samples were then assigned to the subtype of the centroids with the largest correlation coefficient; this procedure is generally referred to as Sorlie's centroid prediction. The same procedure was applied to assign the tumor samples to the five subtypes in the $\mathrm{Hu}$ et al. classification [2], with a set of 213 common genes.

The Cowden signature was obtained by applying a Welch T-test comparing the samples in the Cowden cluster to all the other samples for the 48,927 probe sets retained after filtering. We selected the 3,075 probe sets with a $P$-value $<0.01$ corresponding to a local False-Discovery-Rate of 20\% (R package kerfdr [22]), then applied a random-forest procedure to choose the 200 probe sets best able to divide the samples into two groups, with a $P$-value $<0.001$ ( $\mathrm{R}$ package randomForest [23]) These 200 probe sets are the Cowden signature probe sets.

\section{Gene set analysis}

To define gene sets for pathway analysis, we mapped the biological pathway-related genes, gene ontology (GO) term-related proteins and public gene signatures to non-redundant Entrez Gene identifiers. For each GO term, we obtained a non-redundant list of protein identifiers, either directly associated with the GO term or one of its descendants, and mapped it to a non-redundant list of Entrez Gene ids, GO terms and their relationships (parent/child) [24]. Public signatures were downloaded from the molecular signature database MSigDB [25,26]. We used the hypergeometric test to measure the association between the Cowden signature (Entrez Gene ids) and a biological pathway, a GO term or a public signature, as described in the GOstats $R$ package.

\section{Principal components analysis}

The first two principal components were used to visualize the tumors (ade4 R [27]). The groups of samples identified visually were confirmed by model-based clustering ( $\mathrm{R}$ package mclust [28]). The signature showing transcriptomic differences between Cowden and nonCowden molecular apocrine carcinomas was obtained by applying a Welch T-test to the three Cowden tumors and the two apocrine non-Cowden tumors following the same approach as that for the determination of the Cowden signature.

\section{Statistical tests}

Association of the sample subgroups to bio-clinical factors and to immunohistochemical factors was evaluated by applying a chi-square test (or the equivalent Fisherexact test when appropriate).

The genomic rate of perturbation was defined as the mean, by chromosomal arm, of the ratio between the number of clones lost or gained and the total number of informative clones for each arm.

\section{Results}

\section{Cowden tumors cluster together}

The heatmap obtained after unsupervised clustering of the gene expression data from 74 tumors from patients with a familial clustering of breast cancer is shown in Figure 1. The major branches in the dendrogram correspond to the luminal A, luminal B and basal-like classes in the Stanford classification [4] 


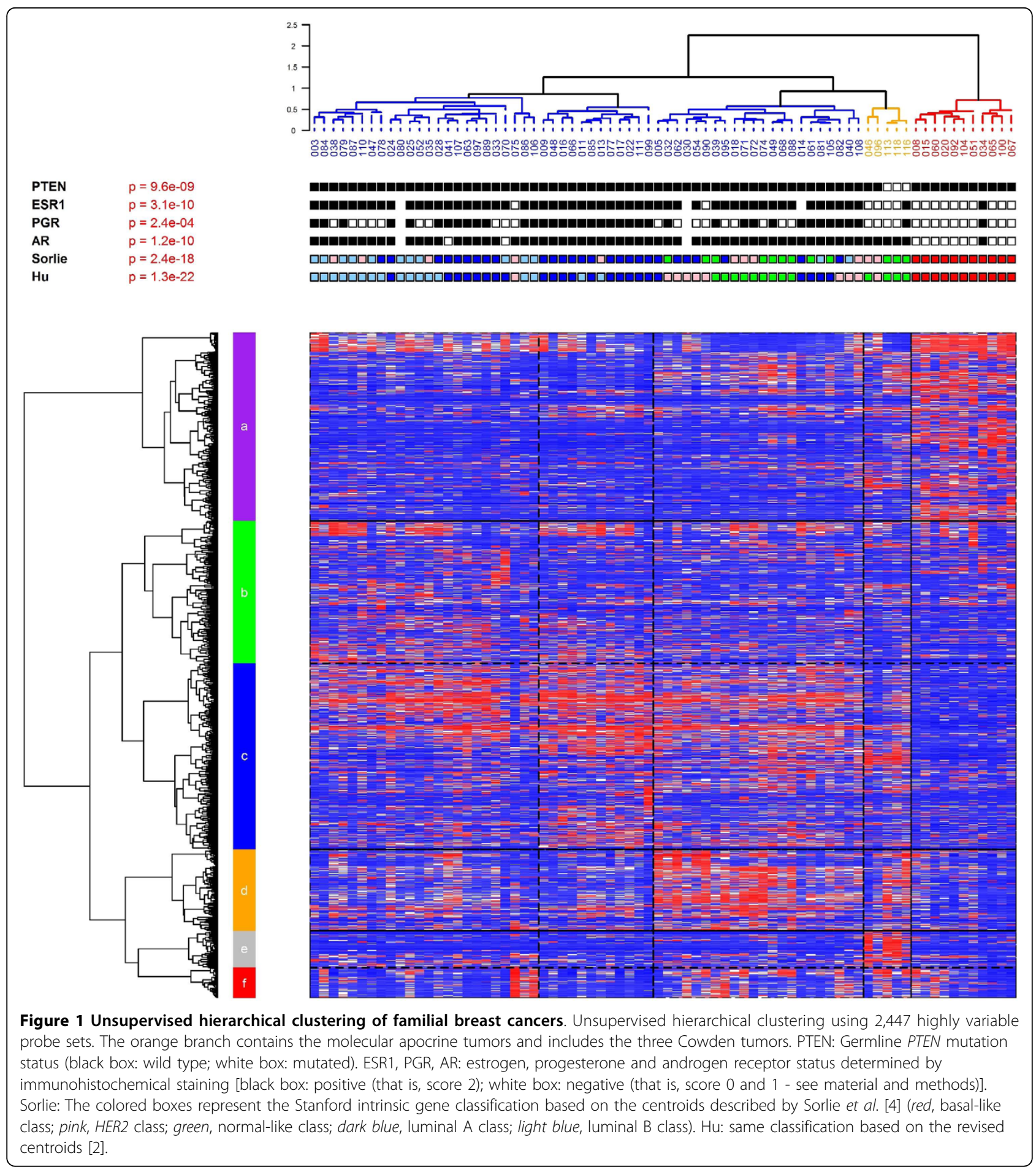

$\left(P=2.4 \times 10^{-18}\right.$ with the Sorlie intrinsic gene set and $P=1.3 \times 10^{-22}$ with the $\mathrm{Hu}$ intrinsic gene set). Interestingly, the three Cowden tumors, along with two supplementary tumors, lie on a separate branch, marked orange in the figure, characterized by overexpression of a group of about 84 genes (cluster e, Figure 1). Correlation with the Stanford centroids [4] was used to classify these tumors. Two were assigned to the HER2 class and three to the normal-like class, indicating that the observed clustering can not be explained by the Stanford model. The two non-Cowden tumors were tested for somatic point mutations and large rearrangements in the PTEN gene, but no abnormalities were detected. 
The Cowden signature is similar to a molecular apocrine signature

To understand the molecular basis for this Cowden-specific clustering, a supervised analysis was performed (Figure 2) identifying a molecular signature of 101 overexpressed genes and 30 underexpressed genes in the Cowden group (Table S2 in Additional file 1). Pathway and Gene Ontology analyses of the Cowden tumors (Table 1) showed enrichment for genes belonging to several metabolic pathways, including lipid metabolism
$\left(P=1 \times 10^{-10}\right)$, PPAR $\gamma$ signaling $\left(P=3 \times 10^{-6}\right)$ and androgen and estrogen metabolism $\left(P=1 \times 10^{-4}\right)$. Comparison with published data [29] showed that there was no overlap between our signature and the Agendia 70gene profile [30] (70 probes) or the OncotypeDx recurrence score [31] (16 genes), and there was only minimal overlap with the Core Serum Response gene set [32] (5 genes in common out of 416 probes). The enrichment in metabolic genes in the Cowden signature is reminiscent of molecular apocrine tumors [33], a tumor type

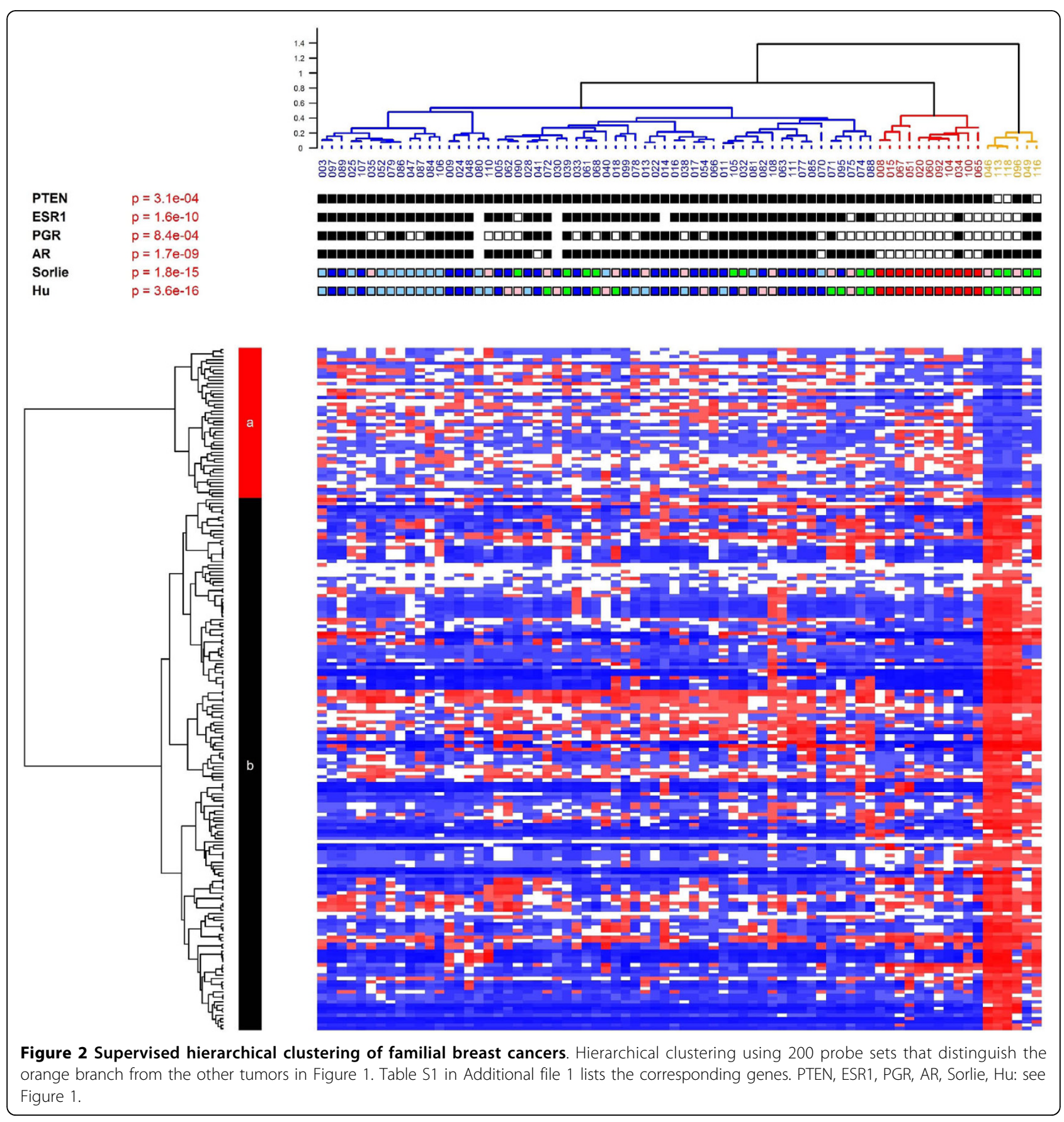


Table 1 Gene ontology enrichment for the Cowden signature and comparison with other signatures

\begin{tabular}{lc}
\hline Gene Ontology interrogation & $P$-value \\
\hline Oxidoreductase activity & $3 \times 10^{-11}$ \\
Lipid metabolic process & $1 \times 10^{-10}$ \\
Cellular lipid metabolic process & $4 \times 10^{-7}$ \\
Carboxylic acid metabolic process & $1 \times 10^{-5}$ \\
Organic acid metabolic process & $1 \times 10^{-5}$
\end{tabular}

KEGG pathway database interrogation

PPAR signaling pathway

Bile acid biosynthesis

Androgen and estrogen metabolism

Arachidonic acid metabolism

Metabolism of xenobiotics by cytochrome P450

$3 \times 10^{-6}$
$6 \times 10^{-5}$
$1 \times 10^{-4}$
$2 \times 10^{-4}$
$4 \times 10^{-4}$

MSig database interrogation

Molecular apocrine signature (Farmer et al.)

Genes upregulated by androgen in neoplastic prostate epithelium (Nelson et al.)

Genes annotated in NetAffx as androgen related (NetAffx) $2 \times 10^{-8}$

Genes downregulated in AIDS-related primary effusion $\quad 2 \times 10^{-4}$

lymphoma (PEL) cells compared to normal B cells and

other tumor subtypes. (Klein et al.)

Genes downregulated by telomerase (Smith et al.)

Downregulated in mature, differentiated adipocytes

following treatment with TNFalpha (Ruan et al.)

suspected to have increased androgenic signaling that overlaps with the HER2 class in the Stanford classification. In total, 54 genes are shared by the Cowden (131 genes) and apocrine (556 genes) signatures [33]. This overlap is highly significant $\left(P=6 \times 10^{-50}\right)$ and substantially greater than with any other signatures we tested (Table 1). A principal components analysis (PCA) (Figure 3) with the genes of the Farmer signature [33] showed that the tumors of our study fall into three discrete groups containing the basal-like, the luminal and the Cowden-like tumors (Figure 3C). The converse is also true: principal components analysis of the Farmer tumors with the Cowden genes identified six Cowdenlike tumors corresponding to the six tumors previously labeled as molecular apocrine subtype (Figure 3B). We conclude that the Cowden and molecular apocrine signatures identify the same tumors.

\section{GGT1 is an immunohistochemical marker for sporadic and Cowden disease breast cancers with apocrine profile}

To test whether apocrine differentiation is a general feature of Cowden disease breast cancers, we examined an additional 12 tumors, for which RNA was not available, by histological and immunohistochemical techniques on a tissue microarray containing the 12 new and the 74 original tumors. To identify antibodies that work on formalin-fixed paraffin-embedded material we screened for antibodies showing the largest difference in mean expression level between the Cowden/apocrine tumor group and the others. The most discriminating antibody was against gamma-glutamlytransferase (GGT1). We also assessed expression of the androgen receptor (AR) and the epidermal growth factor receptor (EGFR) because of their association with the molecular apocrine subtype [33,34], GCDFP15 (PIP), a marker of apocrine differentiation currently used in routine pathological practice [33,35], PTEN itself, and the classic markers ERBB2, estrogen receptor alpha (ER) and progesterone receptor (PR). The results are summarized in Table 2 and detailed in Tables S3 and S4 (Additional file 1). In the initial set of tumors, three have histological features of classic apocrine carcinoma (cases 46,113 and 118), one is an invasive ductal carcinoma with apocrine features (case 96), and the remaining tumor is a poorly differentiated invasive ductal carcinoma without apocrine features (case 116). All of the tumors in this group are strongly positive for GGT1 (Figure 4), and the four tumors with histological apocrine features expressed EGFR (cases 46, 96, 113 and 118). In the new set of Cowden tumors, two have histological features of classic apocrine carcinoma (cases 295 and 891) and are GGT1 positive. Two are invasive ductal (cases 681 and 732), one is a micro papillary carcinoma (case 712), all with apocrine features that do not meet the full criteria for apocrine carcinoma; all three are weakly positive for GGT1. Overall, if one uses a threshold of $1 \%$ of GGT1-stained cells to score tumors as positive, 12 out of the 15 Cowden tumors are positive for GGT1 and only one of 69 in the control group $\left(P=9 \times 10^{-13}\right)$ (Figure 4). GCDFP15 was less useful as a Cowden or apocrine marker since 8 of the 15 Cowden tumors were positive, compared with 14 of the 69 control tumors $(P=0.025)$ (Table 2, Tables S3 and S4 in Additional file 1, and Figure 4). The other markers showed that typical invasive apocrine carcinomas are AR-positive, ERnegative and EGFR positive. The Cowden tumors were all AR-positive but only $27 \%$ were ER-negative, indicating that the phenotype of apocrine carcinomas is not identical to that of Cowden breast cancers. Interestingly, PTEN immunohistochemistry was negative in 13 of the 15 Cowden tumors, compared to only 3 of 69 in the control group. The two non-Cowden molecular apocrine tumors showed clear PTEN positivity. We conclude that breast cancers occurring in women with Cowden disease commonly show apocrine differentiation and that GGT1 appear to be a useful marker to identify molecular apocrine carcinomas.

\section{Molecular apocrine carcinomas have genetic alterations of the ERBB2/PIK3CA/PTEN pathway}

The main genetic lesion associated with molecular apocrine carcinoma in the literature is ERBB2 amplification 

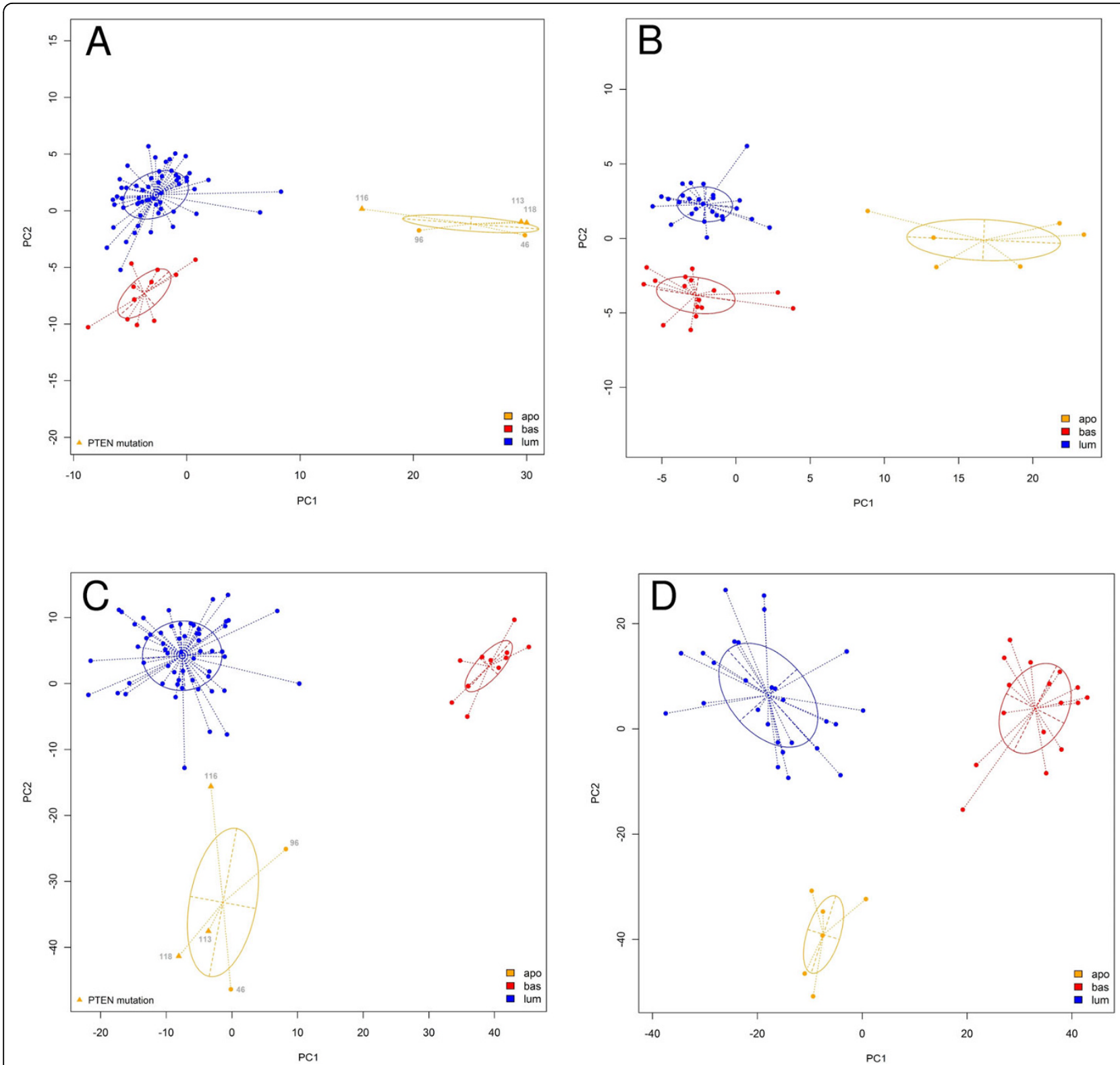

Figure 3 Principal components analysis using the Cowden and molecular apocrine (Farmer) signatures (13). The first two principal components were used to plot the tumors from this study in $\mathbf{A}$ and $\mathbf{C}$, and to plot the tumors from the Farmer study in $\mathbf{B}$ and $\mathbf{D}$. The genes used were derived from the Cowden signature in $A$ and $B$, and from the Farmer signature in $C$ and $D$. In both cases, the signatures from the two studies identify the same tumors.

[33,36,37]. To identify additional lesions, we performed array CGH of the five tumors showing a molecular apocrine profile including the three Cowden tumors. The results are shown in Figure 5. In contrast with typical sporadic breast cancers, the CGH profiles of molecular apocrine Cowden tumors show no major abnormalities, with a genomic perturbation rate of 0.08 , 0.05 and 0.12 , respectively, for tumors 113,116 and 118 , while apocrine non-Cowden tumors show a higher rate of 0.27 and 0.43 , respectively, for tumors 46 and 96
(Table S5 in Additional file 1). By comparison, the mean value of perturbation rate in a series of 135 unselected breast carcinomas is 0.28 (range 0.02 to 0.73 ) (unpublished data). Specifically, gain or loss of large segments of chromosome arms, a defect very commonly seen in sporadic tumors, was only seen in three tumors, and was restricted to chromosomes, $1,8,15,16,19$ and 21 (Figure 5A). On the other hand, many small gains and losses were observed particularly affecting chromosome 17. Only one tumor (case 96) had an amplicon on 
Table 2 Characteristics of the Cowden breast cancers and the non-Cowden apocrine carcinomas

\begin{tabular}{|c|c|c|c|c|c|c|c|c|c|c|c|c|c|}
\hline $\begin{array}{l}\text { Tumor } \\
\text { sample }\end{array}$ & $\begin{array}{l}\text { Cowden } \\
\text { disease }\end{array}$ & $\begin{array}{l}\text { PTEN germline } \\
\text { mutation status }\end{array}$ & $\begin{array}{l}\text { Age at diagnosis } \\
\text { of cancer }\end{array}$ & $\begin{array}{l}\text { Histologic } \\
\text { type }\end{array}$ & $\begin{array}{l}\text { Histologic } \\
\text { grade }\end{array}$ & $\begin{array}{l}\text { Apocrine } \\
\text { features }\end{array}$ & $A R$ & ER & PR & ERBB2 & GCDFP15 & GGT1 & PTEN \\
\hline 46 & No & WT & $60 y$ & IAC & 2 & Yes & 2 & 0 & 0 & 0 & 2 & 2 & 2 \\
\hline 96 & No & WT & $40 y$ & IDC & 3 & Yes & 2 & 0 & 0 & +++ & 2 & 2 & 2 \\
\hline 113 & Yes & $c .209+5 G>A$ & $48 y$ & IAC & 1 & Yes & 2 & 0 & 0 & 0 & 2 & 2 & 0 \\
\hline 116 & Yes & c.1007dupA p.Tyr336X & $44 y$ & IDC & 2 & No & 2 & 2 & 2 & 0 & 0 & 2 & 0 \\
\hline 118 & Yes & $c .209+5 G>A$ & $35 y$ & IAC & 2 & Yes & 2 & 0 & 0 & 0 & 2 & 2 & 0 \\
\hline S89 & Yes & $\begin{array}{l}\text { c.158_159insATAC p. } \\
\text { val54TyrfsX10 }\end{array}$ & 44 y & IDC & 2 & No & 2 & 2 & 2 & 0 & 0 & 0 & 0 \\
\hline S243 & Yes & $\begin{array}{l}\text { c.323T > C p. } \\
\text { Leu108Pro }\end{array}$ & $28 \mathrm{y}$ & IDC & 2 & No & 2 & 2 & 2 & 0 & 0 & 1 & 0 \\
\hline S295 & yes & c. $209+5 G>A$ & $44 \mathrm{y}$ & $I A C$ & 2 & Yes & 2 & 0 & 0 & 0 & 2 & 2 & 0 \\
\hline S362 & Yes & $\begin{array}{l}\text { c.69dupA p. } \\
\text { Asp24ArgfsX20 }\end{array}$ & 53 y & DCIS & low & No & 2 & 2 & 2 & 0 & 0 & 1 & 0 \\
\hline S403 & Yes & c. $801+1$ delG & $43 y$ & IDC & 2 & No & 2 & 2 & 2 & 0 & 0 & 0 & 0 \\
\hline S574 & Yes & $\begin{array}{l}\text { c.491delA p. } \\
\text { Lys164ArgfsX3 }\end{array}$ & $46 y$ & IDC & 1 & No & 2 & 2 & 2 & 0 & 0 & 1 & 0 \\
\hline S681 & Yes & $\begin{array}{l}\text { c. } 830 C>\text { G p. } \\
\text { Thr277Arg }\end{array}$ & $27 y$ & IDC & 3 & Yes & 2 & 2 & 1 & + & 1 & 1 & 0 \\
\hline S712 & Yes & c.592delA p.Met198X & $41 \mathrm{y}$ & MPC & 2 & Yes & 2 & 2 & 0 & nd & 0 & 1 & 0 \\
\hline S730 & Yes & $\begin{array}{l}\text { c.493G > A p. } \\
\text { Gly } 165 \text { Arg }\end{array}$ & $59 y$ & ILC & 2 & No & 2 & 2 & 2 & + & 2 & 0 & 0 \\
\hline S732 & Yes & $\begin{array}{l}\text { c.510T > G p. } \\
\text { Ser170Arg }\end{array}$ & $46 y$ & IDC & 2 & Yes & 2 & 2 & 2 & 0 & 1 & 1 & 1 \\
\hline S891 & yes & c. $209+5 G>A$ & 35 y & IAC & 2 & Yes & 2 & 0 & 0 & ++ & 2 & 2 & 2 \\
\hline S912 & Yes & $\begin{array}{l}\text { c.632_633delGC p. } \\
\text { Cys211X }\end{array}$ & $34 y$ & IDC & 2 & No & 2 & 2 & 2 & 0 & 1 & 1 & 0 \\
\hline
\end{tabular}

IHC status excepted for ERBB2 (0 to +++): 0 = negative; 1 = positive up to $10 \%$ of cells; 2 = positive above $10 \%$ of cells. DCIS, ductal carcinoma in situ; IAC, invasive apocrine carcinoma; IDC, invasive ductal carcinoma; ILC, invasive lobular carcinoma; MPC, micro papillary carcinoma; nd, not determined; WT, wild type.

chromosome 17 that included the ERBB2 gene (Figure $5 \mathrm{C})$. Interestingly, this was one of the two non-Cowden tumors in the molecular apocrine group. One obvious question is whether the CGH profiles for the Cowden tumors show loss of heterozygosity for the PTEN locus. The small genomic rearrangements observed in tumor 118 include a specific loss at the chromosomal band $10 \mathrm{q} 23$ that spans the PTEN gene (Figure 5B). Sequencing of the corresponding tumor DNA confirmed that the deletion eliminates the wild type PTEN allele in that tumor. Although a slight predominance of the mutated allele is observed for tumor 116, no clear evidence for allelic loss was obtained from sequencing and semi quantitative multipex PCR for the two other Cowden tumors (data not shown). It is however difficult to definitively conclude the PTEN allelic status because of normal cell contamination that can mask a loss of genetic material in tumoral cells. Evidence for the loss of the wild type allele in at least one tumor suggests that PTEN behaves like a classic tumor suppressor gene in Cowden tumors. Further support for this model comes from immunohistochemical staining for PTEN, which was reduced or absent in all but the two non-Cowden tumors in the panel tested (Table 2; Figure 4). The loss of the PTEN protein expression associated with the probable retention of the wild type PTEN allele in cases 113 and 116 suggests that additional changes, such as DNA methylation, may eliminate expression of the wild type allele in some cases.

\section{Transcriptomic differences between Cowden tumors and} molecular apocrine carcinomas

Given the relatively flat CGH profiles of the Cowden tumors, which contrast strongly with the expected, amplicon-rich profiles in sporadic molecular apocrine tumors, we performed a supervised analysis of gene expression data to identify potential explanations for the difference between the two tumor types. The results, which should be treated with caution because of the small number of tumors tested, are given in Table S6 and S7 (Additional file 1) and in Figure S1 in Additional file 2 . We identified a signature of 200 probe sets corresponding to 54 genes upregulated in Cowden breast tumors and 110 genes upregulated in non-Cowden apocrine tumors. Pathway and Gene Ontology enrichment analyses indicated that the Cowden tumors preferentially express genes involved in MAPK and JAK-STAT signaling pathways whereas non-Cowden apocrine tumors express genes involved in insulin and calcium signaling pathways. 


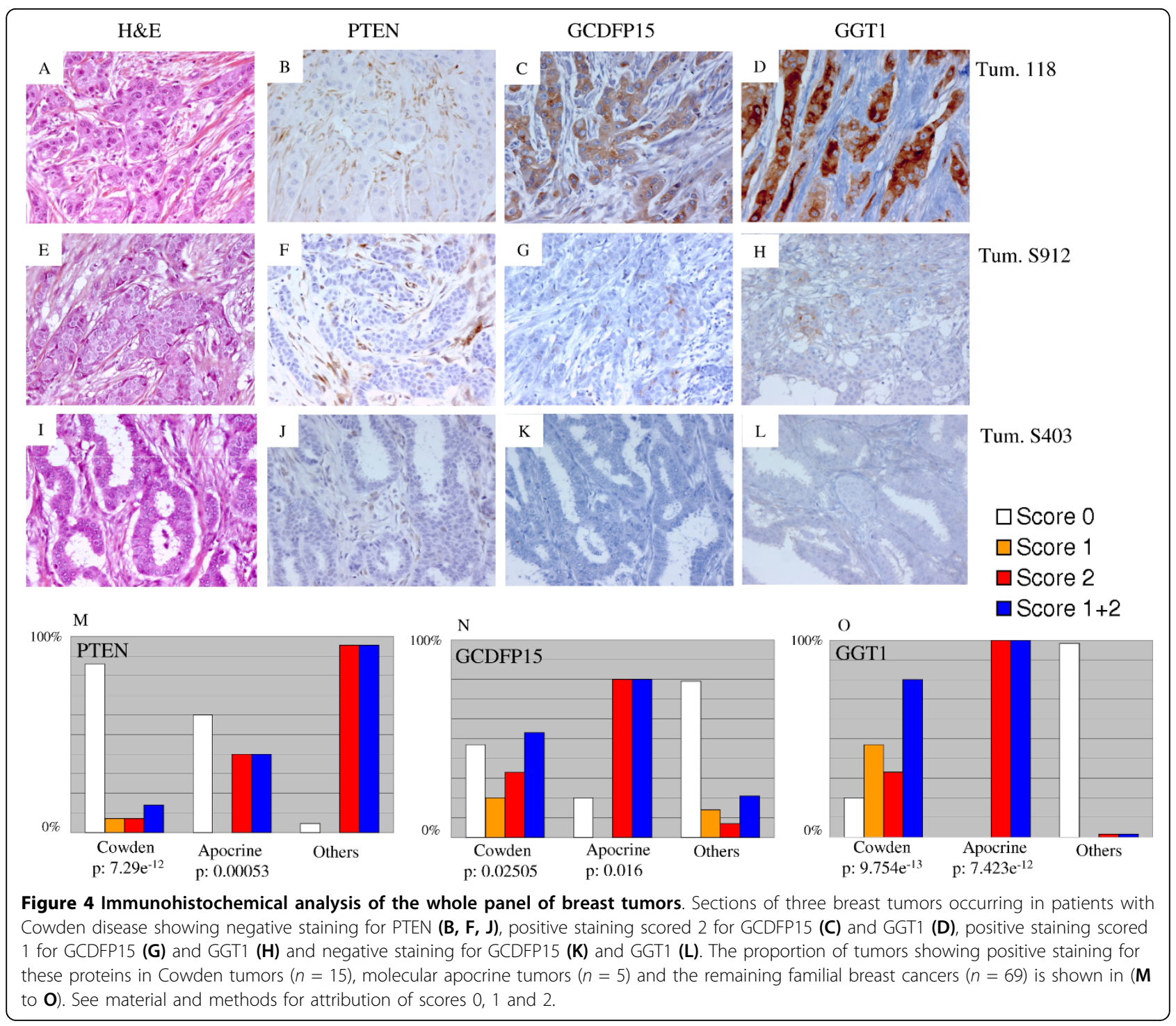

\section{Discussion}

The main conclusion from this study is that germline PTEN mutation predisposes to the formation of breast tumors with apocrine features. This is intriguing because of the large body of work linking ERBB2, PTEN and PI3-kinase signaling to breast cancer. Interestingly, the timing of PTEN loss during tumorigenesis seems to dictate the phenotype, with apocrine features particularly associated with germline PTEN loss.

In the original microarray-based classification of breast cancer, Perou and colleagues identified a group of tumors enriched in ERBB2-amplified tumors that they called the HER2 class [1]. Further analysis of this group on Affymetrix gene expression arrays, which have a broader selection of genes than was available to Perou, confirmed the observation that $E R B B 2$ is commonly amplified $[1,3,4]$, but we proposed the name molecular apocrine for the group to reflect the RNA phenotype [33] and the fact that many ERBB2-amplified tumors lie outside this group. The results of the present study confirm the existence of a molecular apocrine group, and further weaken the argument for using HER2 to label it, because the tumors with this phenotype showing germline PTEN mutations lack ERBB2 amplification.

Apocrine carcinoma is a classic histological subtype of breast carcinoma with characteristic morphological and immunohistochemical features [38,39]. It belongs to a spectrum of apocrine metaplasia including common benign conditions like fibrocystic disease that are associated with increased androgen signaling. In general, the link with androgens is stronger at the benign end of the spectrum, but some malignant tumors in the apocrine group also show increased expression of androgen receptor target genes, and a breast cancer cell line 


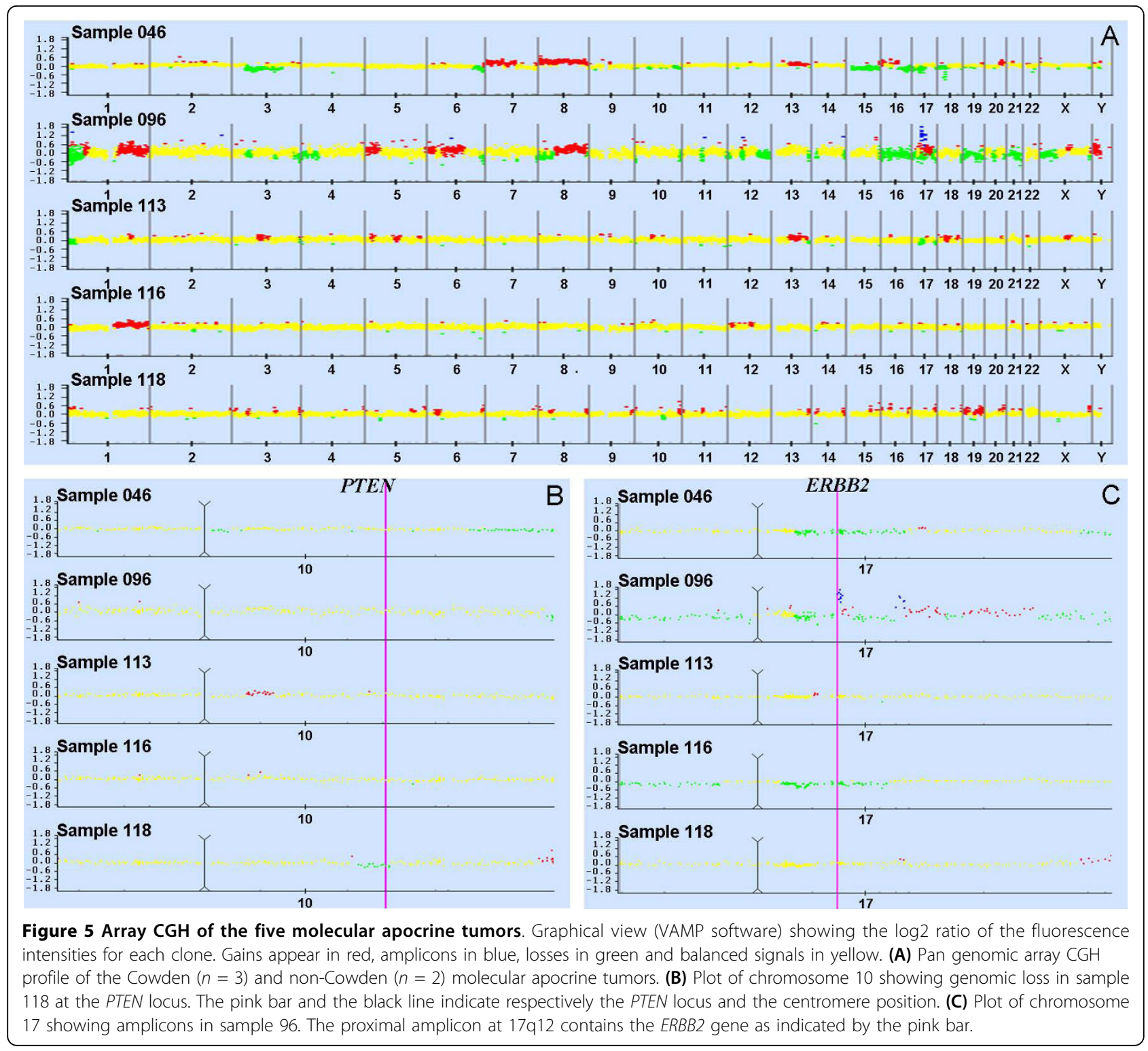

(MDA-MB-453) with a molecular apocrine gene expression profile was recently shown to be androgen-dependent for growth [36]. Interestingly, this cell line has an inactivating PTEN mutation (c.919G > A - p.Glu307Lys) [40]. Classic apocrine carcinoma is not known to be linked to Cowden disease, but benign mammary lesions occurring in Cowden disease frequently show apocrine differentiation [41,42], and 4 of the 15 tumors in our series met the full histological criteria for a diagnosis of apocrine carcinoma. The original molecular apocrine description linked this subtype of tumors to the AR positive and ER negative phenotype. In this series, several Cowden tumors, including tumor 116 that belongs to the Cowden/apocrine transcriptomic cluster are ER positive. This tumor may be an example of the recently described apocrine-like carcinoma which includes AR and ER positive tumors [34]. Additional transcriptomic studies of Cowden breast carcinoma will be necessary to confirm and extend this hypothesis.

The two non-Cowden apocrine carcinomas in this study express a normal level of wild type PTEN, indicating that some other mechanism must explain the apocrine differentiation of these tumors. Interestingly, one of these tumors has amplified the ERBB2 gene and the other has a PIK3CA mutation (c.3140A > G; p. His1047Arg - data not shown). Thus, all five apocrine tumors for which we have RNA, DNA and immunohistochemical data show a specific genetic alteration in the ERBB2-PTEN-PIK3CA pathway. This observation seems to indicate that if the main phenotypic trait of apocrine 
carcinomas is increased androgen signaling, the main genetic trait is mutation of genes in the ERBB2-PTENPIK3CA pathway. The number of tumors is too small to draw a definitive conclusion but the observation is provocative and deserves further study.

The link between PTEN and apocrine differentiation seems not to extend to somatic PTEN mutations. Although rare, somatic PTEN mutations have previously been reported in breast cancer [43,44], but they were seen mainly in the basal-like tumors class characterized by a loss of expression of PTEN [45] and more specifically in tumors from patients with $B R C A 1$ mutations [40]. The 74 familial breast cancers microarrayed in this study include seven linked to $B R C A 1$ and five linked to $B R C A 2$. None of these tumors has a molecular apocrine profile. In the same way, tumors 9,11 and 15 have lost PTEN expression (Table S2 in Additional file 1) but do not have a molecular apocrine profile (luminal A for tumors 9 and 11; basal-like for tumor 15). Thus, somatic PTEN mutation appears not to be directly linked to apocrine differentiation in our panel of familial tumors. To formally exclude a role in sporadic tumors, a specific study of PTEN alterations in sporadic apocrine carcinoma should be done.

The mechanism leading from germline PTEN mutation to apocrine differentiation is unknown, but there are numerous hints in the literature. First, PTEN has been shown to inhibit androgen receptor-driven transcription in LNCaP prostate cancer cells in an AKTdependent or independent manner [46,47]. Loss of $P T E N$ in this model increases androgen signaling, which is itself a feature of apocrine cells. Second, ERBB2 amplification is commonly seen in sporadic tumors in the molecular apocrine class. ERBB2 has been shown to stabilize AR protein in prostate cancer cells [48] and to activate the Akt pathway [49]. Third, in a large-scale RNA interference screen, PTEN silencing conferred resistance to trastuzumab in breast cancer cells with ERBB2 amplification [50]. Fourth, PTEN-deficient/ Erbb2 ${ }^{\mathrm{KI}}$ transgenic mice show accelerated mammary tumor onset associated with elevated ERBB2 protein levels that are not caused by ERBB2 amplification [51]. A subset of the mouse tumors has large nuclei, prominent nucleoli and abundant cytoplasm, the hallmarks of apocrine histology. This confirms that increased ERBB2 signaling in the context of germline PTEN loss predisposes to apocrine tumorigenesis, and provides a transgenic mouse model to study apocrine breast cancer. Finally, the Gene Ontology analysis in Table 1 links the Cowden signature to increased PPAR $\gamma$ signaling. PPAR $\gamma$ has previously been linked with the PTEN pathway [52], it transactivates the PTEN promoter [53], and PPAR $\gamma$ agonists increase PTEN expression in breast cancer cell lines. Activation of the PPAR $\gamma$ pathway following loss of PTEN could be explained by negative feedback of PTEN on PPAR $\gamma$.

\section{Conclusions}

Taken together, our results in Cowden disease and multiple results in the literature strongly support a central role for the ERBB2-PTEN-PIK3CA-AKT pathway in the biology of breast cancer. We suspect that loss of PTEN early in tumorigenesis leads to the expansion of a cell in the hierarchy of mammary differentiation with a pronounced tendency to undergo apocrine metaplasia. Current models for mammary differentiation would place this cell at a late point in the hierarchy, after the luminal progenitor stage [54].

\section{Additional material}

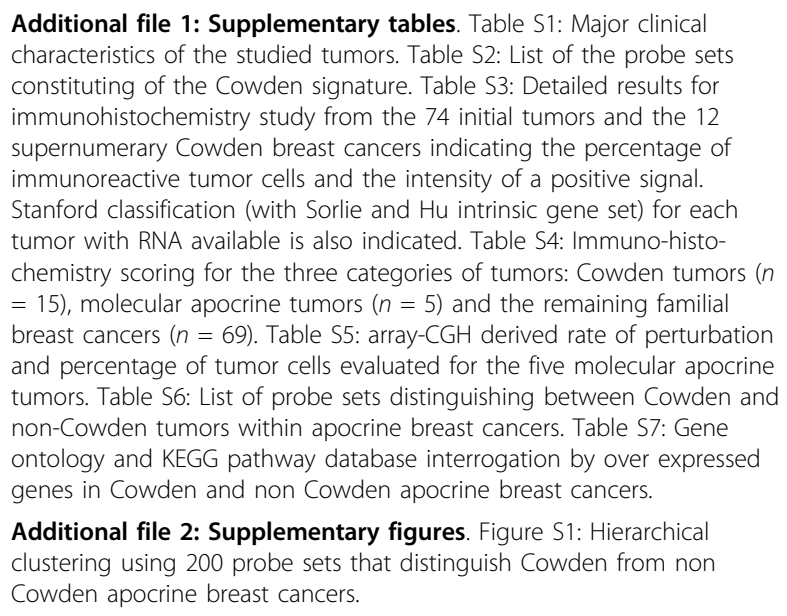

Additional file 2: Supplementary figures. Figure S1: Hierarchical clustering using 200 probe sets that distinguish Cowden from non Cowden apocrine breast cancers.

\section{Abbreviations}

AR: androgen receptor; CY5: cyanine 5; CY3: cyanine 3; EGFR: epidermal growth factor receptor; ER: estrogen receptor; GO: gene ontology; P: probe sets; PCA: principal components analysis; RCV: robust coefficient of variation; RMA: robust multi-array average; Varmed: median of the variances.

\section{Competing interests}

The authors declare that they have no competing interests.

\section{Authors' contributions}

ML, FB and NS planned and supervised the work. GB performed the experiments, except for immunohistochemistry. GB and RS managed the data. W performed TMA and immunohistochemistry experiments. IDM and GMG read immunohistochemistry slides. FC, VB, AD, CD, BG, OI and PV provided samples from Cowden patients with breast cancer. MG, GB, ADR and RI performed statistical and bioinformatic analyses. GB, GMG, MG, RI and $\mathrm{ML}$ wrote the manuscript.

\section{Acknowledgements}

We thank the patients and their families who contributed to this study. We thank Laurent Arnoult, Catherine Clement-Chassagne, Sophie Guymar, Pierre Le Villain, Beaudoin Mazet, Brigitte Sigal-Zafrani, Patrick Tass and JeanLaurent Totobenazara for providing paraffin-embedded tumor blocks. The 
expertise of the members of the Affymetrix expression array platform at IGBMC, Strasbourg is gratefully acknowledged.

This work is part of the national program "Cartes d'Identité des Tumeurs" [10] funded and developed by the "Ligue Nationale contre le Cancer". We thank the Charente Maritime Cancer League, the Pyrenees Atlantiques Cancer League, the Canceropole Grand Sud-Ouest (ACl 2004 renewed 2007) and the Bergerac Lions Club for funding to ML. We thank the French Foundation for Medical Research (FRM) and the Bergonié Cancer Institute for funding to $\mathrm{GB}$.

\section{Author details}

'INSERM U916, Université de Bordeaux, Institut Bergonié, 229 cours de I'Argonne, 33000, Bordeaux, France. ${ }^{2}$ Tumor Identity Card program (CIT3), Ligue Nationale Contre le Cancer, 12 rue Corvisart, 75013 Paris, France. ${ }^{3}$ Pathology Department, Institut Bergonié, 229 cours de l'Argonne, 33000, Bordeaux, France. ${ }^{4}$ Cancer Genetics Unit, Centre Léon Bérard, 28 rue Laennec, 69008 Lyon, France. ${ }^{5}$ Medical Genetics Unit, CHU de Nantes, 5 allée de I'Île Gloriette, 44000 Nantes, France. ${ }^{6}$ Cancer Genetics Unit, Centre Eugène Marquis, avenue de la Bataille Flandres-Dunkerque, 35000 Rennes, France. ${ }^{7}$ Medical Genetics Unit, CHU de Poitiers, 2 rue Milétrie, 86000 Poitiers, France. ${ }^{8}$ Medical Genetics Unit, CHU d'Angers, rue Larrey, 49100 Angers, France. ${ }^{9}$ Dermatology Department, CHU de Dijon, 2 boulevard du Maréchal de Lattre de Tassigny, 21000 Dijon, France. ${ }^{10}$ Dermatology Department, Hôpital Avicenne, 125 rue Stalingrad, 93000 Bobigny, France. ${ }^{11}$ Cancer Genetics Unit, Institut Bergonié, 229 cours de l'Argonne, 33000 Bordeaux, France.

Received: 19 April 2010 Revised: 7 July 2010 Accepted: 16 August 2010 Published: 16 August 2010

\section{References}

1. Perou CM, Sorlie T, Eisen MB, van de Rijn M, Jeffrey SS, Rees CA, Pollack JR, Ross DT, Johnsen $\mathrm{H}$, Akslen LA, Fluge O, Pergamenschikov A, Williams $C$, Zhu SX, Lonning PE, Borresen-Dale AL, Brown PO, Botstein D: Molecular portraits of human breast tumours. Nature 2000, 406:747-752.

2. Hu Z, Fan C, Oh DS, Marron JS, He X, Qaqish BF, Livasy C, Carey LA, Reynolds E, Dressler L, Nobel A, Parker J, Ewend MG, Sawyer LR, Wu J, Liu Y, Nanda R, Tretiakova M, Ruiz Orrico A, Dreher D, Palazzo JP, Perreard L, Nelson E, Mone M, Hansen H, Mullins M, Quackenbush JF, Ellis MJ, Olopade OI, Bernard PS, et al: The molecular portraits of breast tumors are conserved across microarray platforms. BMC Genomics 2006, 7:96.

3. Sorlie T, Perou CM, Tibshirani R, Aas T, Geisler S, Johnsen H, Hastie T, Eisen MB, van de Rijn M, Jeffrey SS, Thorsen T, Quist H, Matese JC, Brown PO, Botstein D, Eystein Lonning P, Borresen-Dale AL: Gene expression patterns of breast carcinomas distinguish tumor subclasses with clinical implications. Proc Natl Acad Sci USA 2001, 98:10869-10874.

4. Sorlie T, Tibshirani R, Parker J, Hastie T, Marron JS, Nobel A, Deng S, Johnsen H, Pesich R, Geisler S, Demeter J, Perou CM, Lonning PE, Brown PO, Borresen-Dale AL, Botstein D: Repeated observation of breast tumor subtypes in independent gene expression data sets. Proc Natl Acad Sci USA 2003, 100:8418-8423.

5. Stefansson OA, Jonasson JG, Johannsson OT, Olafsdottir K, Steinarsdottir M, Valgeirsdottir S, Eyfjord JE: Genomic profiling of breast tumours in relation to BRCA abnormalities and phenotypes. Breast Cancer Res 2009, 11:R47.

6. Marsh DJ, Coulon V, Lunetta KL, Rocca-Serra P, Dahia PL, Zheng Z, Liaw D, Caron S, Duboue B, Lin AY, Richardson AL, Bonnetblanc JM, Bressieux JM, Cabarrot-Moreau A, Chompret A, Demange L, Eeles RA, Yahanda AM, Fearon ER, Fricker JP, Gorlin RJ, Hodgson SV, Huson S, Lacombe D, Eng C: Mutation spectrum and genotype-phenotype analyses in Cowden disease and Bannayan-Zonana syndrome, two hamartoma syndromes with germline PTEN mutation. Hum Mol Genet 1998, 7:507-515.

7. Nelen MR, Padberg GW, Peeters EA, Lin AY, van den Helm B, Frants RR, Coulon V, Goldstein AM, van Reen MM, Easton DF, Eeles RA, Hodgsen S, Mulvihill JJ, Murday VA, Tucker MA, Mariman EC, Starink TM, Ponder BA, Ropers HH, Kremer H, Longy M, Eng C: Localization of the gene for Cowden disease to chromosome 10q22-23. Nat Genet 1996, 13:114-116.

8. Starink TM, van der Veen JP, Arwert F, de Waal LP, de Lange GG, Gille JJ, Eriksson AW: The Cowden syndrome: a clinical and genetic study in 21 patients. Clin Genet 1986, 29:222-233.

9. ArrayExpress. [http://www.ebi.ac.uk/microarray-as/ae/].
10. CIT. [http://cit.ligue-cancer.net/index.php/en].

11. Zhou XP, Li YJ, Hoang-Xuan K, Laurent-Puig P, Mokhtari K, Longy M, Sanson M, Delattre JY, Thomas G, Hamelin R: Mutational analysis of the PTEN gene in gliomas: molecular and pathological correlations. Int $J$ Cancer 1999, 84:150-154.

12. Charbonnier F, Raux G, Wang Q, Drouot N, Cordier F, Limacher JM, Saurin JC, Puisieux A, Olschwang S, Frebourg T: Detection of exon deletions and duplications of the mismatch repair genes in hereditary nonpolyposis colorectal cancer families using multiplex polymerase chain reaction of short fluorescent fragments. Cancer Res 2000, 60:2760-2763.

13. Integragen. [http://www.integragen.com].

14. CAPWeb. [http://bioinfo-out.curie.fr/CAPweb/].

15. VAMP. [http://bioinfo.curie.fr/vamp].

16. La Rosa P, Viara E, Hupe P, Pierron G, Liva S, Neuvial P, Brito I, Lair S, Servant N, Robine N, Manie E, Brennetot C, Janoueix-Lerosey I, Raynal V, Gruel N, Rouveirol C, Stransky N, Stern MH, Delattre O, Aurias A, Radvanyi F, Barillot E: VAMP: visualization and analysis of array-CGH, transcriptome and other molecular profiles. Bioinformatics 2006, 22:2066-2073.

17. R-project - V2.9.1. [http://www.R-project.org].

18. Gentleman RC, Carey VJ, Bates DM, Bolstad B, Dettling M, Dudoit S, Ellis B, Gautier L, Ge Y, Gentry J, Hornik K, Hothorn T, Huber W, lacus S, Irizarry R, Leisch F, Li C, Maechler M, Rossini AJ, Sawitzki G, Smith C, Smyth G, Tierney L, Yang JY, Zhang J: Bioconductor: open software development for computational biology and bioinformatics. Genome Biol 2004, 5:R80.

19. Irizarry RA, Hobbs B, Collin F, Beazer-Barclay YD, Antonellis KJ, Scherf U, Speed TP: Exploration, normalization, and summaries of high density oligonucleotide array probe level data. Biostatistics 2003, 4:249-264.

20. BRB ArrayTools. [http://linus.nci.nih.gov/BRB-ArrayTools.html].

21. Robustness. [http://genome-www.stanford.edu/breast_cancer/robustness].

22. Guedj M, Robin S, Celisse A, Nuel G: Kerfdr: a semi-parametric kernelbased approach to local false discovery rate estimation. BMC Bioinformatics 2009, 10:84.

23. Breiman L: Random forests. Machine Learning 2001, 45:5-32.

24. EBI FTP Server. [ftp://ftp.ebi.ac.uk/pub/databases/GO/goa].

25. MSigDB. [http://www.broadinstitute.org/gsea/msigdb].

26. Subramanian A, Tamayo P, Mootha VK, Mukherjee S, Ebert BL, Gillette MA, Paulovich A, Pomeroy SL, Golub TR, Lander ES, Mesirov JP: Gene set enrichment analysis: a knowledge-based approach for interpreting genome-wide expression profiles. Proc Natl Acad Sci USA 2005, 102:15545-15550.

27. Dray S, Dufour AB: The ade4 package: implementing the duality diagram for ecologists. Journal of Statistical Software 2007, 22:1-20.

28. Fraley C, Raftery AE: Model-based clustering, discriminant analysis, and density estimation. Journal of the American Statistical Association 2002, 97:611-631.

29. Fan C, Oh DS, Wessels $L$, Weigelt $B$, Nuyten DS, Nobel AB, van't Veer $L$, Perou CM: Concordance among gene-expression-based predictors for breast cancer. N Engl J Med 2006, 355:560-569.

30. van't Veer LJ, Dai H, van de Vijver MJ, He YD, Hart AAM, Mao M, Peterse HL, van der Kooy K, Marton MJ, Witteveen AT, Schreiber GJ, Kerkhoven RM, Roberts C, Linsley PS, Bernards R, Friend SH: Gene expression profiling predicts clinical outcome of breast cancer. Nature 2002, 415:530-536.

31. Paik S, Shak S, Tang G, Kim C, Baker J, Cronin M, Baehner FL, Walker MG, Watson D, Park T, Hiller W, Fisher ER, Wickerham DL, Bryant J, Wolmark N: A multigene assay to predict recurrence of tamoxifen-treated, nodenegative breast cancer. N Engl J Med 2004, 351:2817-2826.

32. Chang HY, Sneddon JB, Alizadeh AA, Sood R, West RB, Montgomery K, Chi JT, van de Rijn M, Botstein D, Brown PO: Gene expression signature of fibroblast serum response predicts human cancer progression: similarities between tumors and wounds. PLOS Biol 2004, 2:E7.

33. Farmer $P$, Bonnefoi $H$, Becette $V$, Tubiana-Hulin $M$, Fumoleau $P$, Larsimont D, Macgrogan G, Bergh J, Cameron D, Goldstein D, Duss S, Nicoulaz AL, Brisken C, Fiche M, Delorenzi M, Iggo R: Identification of molecular apocrine breast tumours by microarray analysis. Oncogene 2005, 24:4660-4671.

34. Vranic S, Tawfik O, Palazzo J, Bilalovic J, Eyzaguirre E, Lee LMJ, Adegboyega P, Hagenkord J, Gatalica Z: EGFR and HER-2/neu expression in invasive apocrine carcinoma of the breast. Mod Pathol 2010, 23:644-653. 
35. Mazoujian G, Pinkus GS, Davis S, Haagensen DE Jr: Immunohistochemistry of a gross cystic disease fluid protein (GCDFP-15) of the breast. A marker of apocrine epithelium and breast carcinomas with apocrine features. Am J Pathol 1983, 110:105-112.

36. Doane AS, Danso M, Lal P, Donaton M, Zhang L, Hudis C, Gerald WL: An estrogen receptor-negative breast cancer subset characterized by a hormonally regulated transcriptional program and response to androgen. Oncogene 2006, 25:3994-4008.

37. Naderi A, Hughes-Davies L: A functionally significant cross-talk between androgen receptor and ErbB2 pathways in estrogen receptor negative breast cancer. Neoplasia 2008, 10:542-548.

38. Celis JE, Cabezon T, Moreira JM, Gromov P, Gromova I, TimmermansWielenga V, Iwase T, Akiyama F, Honma N, Rank F: Molecular characterization of apocrine carcinoma of the breast: Validation of an apocrine protein signature in a well-defined cohort. Mol Oncol 2009.

39. O'Malley FP, Bane A: An update on apocrine lesions of the breast. Histopathology 2008, 52:3-10.

40. Saal LH, Gruvberger-Saal SK, Persson C, Lovgren K, Jumppanen M, Staaf J, Jonsson G, Pires MM, Maurer M, Holm K, Koujak S, Subramaniyam S, VallonChristersson J, Olsson H, Su T, Memeo L, Ludwig T, Ethier SP, Krogh M, Szabolcs M, Murty W, Isola J, Hibshoosh H, Parsons R, Borg A: Recurrent gross mutations of the PTEN tumor suppressor gene in breast cancers with deficient DSB repair. Nat Genet 2008, 40:102-107.

41. Schrager CA, Schneider D, Gruener AC, Tsou HC, Peacocke M: Clinical and pathological features of breast disease in Cowden's syndrome: an underrecognized syndrome with an increased risk of breast cancer. Hum Pathol 1998, 29:47-53.

42. Schrager CA, Schneider D, Gruener AC, Tsou HC, Peacocke M: Similarities of cutaneous and breast pathology in Cowden's Syndrome. Exp Dermatol 1998, 7:380-390

43. Bonneau D, Longy M: Mutations of the human PTEN gene. Hum Mut 2000, 16:109-122.

44. COSMIC - Catalogue of Somatic Mutations in Cancer. [http://www.sanger. ac.uk/perl/genetics/CGP/cosmic/].

45. Marty B, Maire V, Gravier E, Rigaill G, Vincent-Salomon A, Kappler M, Lebigot I, Djelti F, Tourdes A, Gestraud P, Hupe P, Barillot E, Cruzalegui F, Tucker GC, Stern MH, Thiery JP, Hickman JA, Dubois T: Frequent PTEN genomic alterations and activated phosphatidylinositol 3-kinase pathway in basal-like breast cancer cells. Breast Cancer Res 2008, 10:R101.

46. Lin HK, Hu YC, Lee DK, Chang C: Regulation of androgen receptor signaling by PTEN (phosphatase and tensin homolog deleted on chromosome 10) tumor suppressor through distinct mechanisms in prostate cancer cells. Mol Endocrinol 2004, 18:2409-2423.

47. Nan B, Snabboon T, Unni E, Yuan J, Whang YE, Marcelli M: The PTEN tumor suppressor is a negative modulator of androgen receptor transcriptional activity. J Mol Endocrinol 2003, 31:169-183.

48. Mellinghoff IK, Vivanco I, Kwon A, Tran C, Wongvipat J, Sawyers CL: HER2/ neu kinase-dependent modulation of androgen receptor function through effects on DNA binding and stability. Cancer Cell 2004, 6:517-527.

49. Holbro T, Beerli RR, Maurer F, Koziczak M, Barbas CF III, Hynes NE: The ErbB2/ErbB3 heterodimer functions as an oncogenic unit: ErbB2 requires ErbB3 to drive breast tumor cell proliferation. Proc Natl Acad Sci USA 2003, 100:8933-8938

50. Berns K, Horlings HM, Hennessy BT, Madiredjo M, Hijmans EM, Beelen K, Linn SC, Gonzalez-Angulo AM, Stemke-Hale K, Hauptmann M, Beijersbergen RL, Mills GB, van de Vijver MJ, Bernards R: A functional genetic approach identifies the PI3K pathway as a major determinant of trastuzumab resistance in breast cancer. Cancer Cell 2007, 12:395-402.

51. Dourdin N, Schade B, Lesurf R, Hallett M, Munn RJ, Cardiff RD, Muller WJ: Phosphatase and tensin homologue deleted on chromosome 10 deficiency accelerates tumor induction in a mouse model of ErbB-2 mammary tumorigenesis. Cancer Res 2008, 68:2122-2131.

52. Patel L, Pass I, Coxon P, Downes CP, Smith SA, Macphee CH: Tumor suppressor and anti-inflammatory actions of PPARgamma agonists are mediated via upregulation of PTEN. Curr Biol 2001, 11:764-768.

53. Teresi RE, Shaiu CW, Chen CS, Chatterjee VK, Waite KA, Eng C: Increased PTEN expression due to transcriptional activation of PPARgamma by Lovastatin and Rosiglitazone. Int J Cancer 2006, 118:2390-2398.

54. Lim E, Vaillant F, Wu D, Forrest NC, Bhupinder P, Hart AH, Asselin-Labat ML, Gyorki DE, Ward T, Partanen A, Feleppa F, Huschtscha LI, Thorne $\mathrm{HJ}$; kConFab, Fox SB, Yan M, French JD, Brown MA, Smyth GK, Visvader JE,
Lindeman GJ: Aberrant luminal progenitors as the candidate target population for basal tumor development in BRCA1 mutation carriers. Nat Med 2009, 15:907-915.

doi: $10.1186 / \mathrm{bcr} 2626$

Cite this article as: Banneau et al: Molecular apocrine differentiation is a common feature of breast cancer in patients with germline PTEN mutations. Breast Cancer Research 2010 12:R63.

\section{Submit your next manuscript to BioMed Central and take full advantage of:}

- Convenient online submission

- Thorough peer review

- No space constraints or color figure charges

- Immediate publication on acceptance

- Inclusion in PubMed, CAS, Scopus and Google Scholar

- Research which is freely available for redistribution
C Biomed Central 